\title{
Assessing Exposure to Bullying through Digital Devices in Working Life: Two Versions of a Cyberbullying Questionnaire (CBQ)
}

\author{
Sandra Jönsson ${ }^{1}$, Tuija Muhonen', Rebecka Cowen Forssell'1, Martin Bäckström² \\ ${ }^{1}$ Centre for Work Life Studies, Malmö University, Malmö, Sweden \\ ${ }^{2}$ Department of Psychology, Lund University, Lund, Sweden \\ Email: sandra.jonsson@mah.se
}

How to cite this paper: Jönsson, S., Muhonen, T., Forssell, R. C., \& Bäckström, M. (2017). Assessing Exposure to Bullying through Digital Devices in Working Life: Two Versions of a Cyberbullying Questionnaire (CBQ). Psychology, 8, 477-494. https://doi.org/10.4236/psych.2017.83030

Received: January 2, 2017

Accepted: February 24, 2017

Published: February 27, 2017

Copyright $\odot 2017$ by authors and Scientific Research Publishing Inc. This work is licensed under the Creative Commons Attribution International License (CC BY 4.0).

http://creativecommons.org/licenses/by/4.0/

\begin{abstract}
The aim of this study is two folded: 1) to analyze the reliability and validity of a cyberbullying behaviour questionnaire (CBQ) in working life and 2) to analyze the reliability and validity of a short version of a cyberbullying behaviour questionnaire (CBQ-S) in working life. A total of 3371 working adults $\left(M_{A g e}=\right.$ 49.85 years $)$ in Sweden, and $238\left(M_{\text {Age }}=35.61\right.$ years $)$ in the USA participated in the study. The results of the Exploratory Structural Equation Modeling (ESEM) showed that the one-factor model had an excellent fit to data, and Cronbach's alpha indicates that both scales are reliable. In addition, the criterion validity of the scales was demonstrated by significant correlations with the following theoretically relevant concepts: wellbeing, work engagement and intention to quit. The results of the study support the use of the CBQ and CBQ-S as reliable and valid measures of cyberbullying behaviour in working life.
\end{abstract}

\section{Keywords}

Cyberbullying Behaviour, Working Life, Psychometric Properties

\section{Introduction}

Communication over the Internet has become a part of everyday life. Approximately $82 \%$ of the Swedish population between 26 and 65 years of age go online everyday (Findahl, 2014). The development of portable devices such as laptops, smartphones, tablet computers, together with the increasing access to Wi-Fi enables people to go online and be connected anywhere, at any time. Even communication in workplaces increasingly takes place electronically, not only through e-mails and text messages, but also through social media such as Facebook, 
Twitter, social forums and digital communities.

Digital communication that has harassing features has been labeled as cyberbullying or online harassment (Wolak, Mitchell, \& Finkelhor, 2007). Whereas cyberbullying refers to online negative acts that are repeated over time, online harassment relates to more unique, once-only acts or behaviour.

Cyberbullying among children and adolescents is a relatively well-known phenomenon. Several studies have been carried out among youngsters (Beran, 2005; Erdur-Baker, 2010; Slonje \& Smith, 2008), while the phenomenon appears to be virtually unexplored among adults in working life (Bartlett \& Bartlett, 2011; Göransson, Näswall, \& Sverke, 2011; Privitera \& Campbell, 2009). Yet, there are indications that online negative acts do not apply only to children and adolescents in school environment, but are something that also occur at the workplace (Lim \& Teo, 2009; Privitera \& Campbell, 2009; Sprigg, Axtell, Coyne, \& Farley, 2012). Due to the limited number of studies of cyberbullying among working adults, we refer in our literature review to studies conducted among youngsters/adolescents.

\subsection{Cyberbullying and Face-to-Face Bullying}

Today, there is an ongoing debate as to what extent cyberbullying is the same or a different phenomenon from face-to-face bullying (Slonje \& Smith, 2008). When it comes to defining face-to-face workplace bullying, most researchers agree that 1) the negative acts are conducted repeatedly and systematically over time and 2) the individuals exposed to the acts have difficulties defending themselves (Einarsen, Hoel, Zapf, \& Cooper, 2011). In the area of cyberbullying among youngsters, the following definition has been used: "an aggressive intentional act carried out by a group or individual, using electronic forms of contact, repeatedly and over time against a victim who cannot easily defend him or herself" (Smith, Mahdavi, Carvalho, Fisher, Russel, \& Tippett, 2008: p. 376). In some parts of the literature, it has been suggested that cyberbullying is just an extension of face-to-face bullying and that the primary difference is that the negative acts have found new channels through digital devices (Olweus, 2013). On the other hand, cyberbullying has also been suggested to be a different phenomenon from face-to-face bullying; that the behaviors, the nature, and consequences of cyberbullying are different from face-to-face bullying (e.g. Runions, Shapka, Dooley, \& Modecki, 2013; Wang, Nansel, \& Iannotti, 2011).

Cyberbullying behaviors can be communicated via text or images through different digital media. Their common denominators are that they can be easily stored, shared, and viewed repeatedly. Among special characteristics of cyberbullying are high accessibility, large potential audience, and the anonymity and invisibility of the perpetrators (Kowalski, Giumetti, Schroder, \& Lattaner, 2014; Slonje \& Smith, 2008). High accessibility through digital devices makes it difficult to avoid the negative acts since the bullied individual can be targeted outside the workplace and after office hours. The negative acts can continue, or even begin, when the workday is actually over. As people are continuously connected to 
the Internet, the victims of online harassment can be targeted whenever and wherever, making them more vulnerable, since there is no "safe haven." On social media the online negative acts can be shared and viewed several times by the audience. This in turn generates questions about what is to be considered as repetition in cyberbullying (Slonje \& Smith, 2008). For example, if a picture or a video clip is uploaded to a particular webpage, it could be argued that every hit on that webpage could be counted as repetition. Further, not seeing the facial and bodily responses of the target tends to decrease feelings of empathy (Kowalski et al., 2014; Slonje \& Smith, 2008). It can be assumed that this encourages the perpetrator to engage in gradually more severe negative acts. Cyberbullying also involves a certain amount of anonymity. By using pseudonyms, or, hijacking someone's identity online, the perpetrator can send harassing messages without revealing his/her identity.

Previous research shows extensive variation in the prevalence of workplace bullying both between and within countries (Agervold, 2007; Nielsen et al., 2009). While Scanidinavian countries show a prevalence rate between $3.5 \%$ and 16\% (Einarsen \& Skogstad, 1996; Mikkelsen \& Einarsen, 2001) a Turkish study reported the prevalence of bullying among white-collar workers as $51 \%$ (Bilgel, Aytac, \& Bayram, 2006). The varitation the rates of prevalence have been explained with reference to cultural differences as well as methodological differences (Nielsen et al., 2009). The limited amount of studies investigating cyberbullying in working life indicate a variety in prevalence rates, ranging from $9 \%$ to 21\% (Baruch, 2005; Brack \& Caltabiano, 2014; Sprigg, Axtell, Coyne, \& Farley, 2012), and a methodological inconsitency in measuring exposure (Forssell, 2016).

Studies of gender differences in victimization concerning face-to-face workplace bullying have shown contradictory results. An analysis of 53 studies showed that $62.5 \%$ of victims were women (Hoel \& Vartia; Zapf, Escartin, \& Einarsen, 2011) but several other studies indicate that men and women's exposure to bullying has a more equal distribution (Einarsen et al., 2011; Leymann, 1996; Notelaers, Vermunt, Baillien, Einarsen, \& Witte, 2011). With regard to the type of bullying behaviors, there are indications that women more often engage in social manipulation, e.g. affecting communication and social reputation, whereas men's bullying is focused on the targeted person's performance at work (Salin \& Hoel, 2013). If there are gender differences when it comes to cyberbullying remains yet to be investigated.

As regards the consequences of face-to-face workplace bullying, it is clear that in addition to the suffering of the victim it effects both the organization and the society. For the individual, workplace bullying has proven to be related to adverse health effects (Zapf \& Einarsen, 2001). The organizational consequences include declining efficiency, reduced creativity, increased absenteeism and staff turnover (Göransson et al., 2011). In addition, a meta-analysis of the outcomes of workplace bullying, Nielsen and Einarsen (2012) found that exposure to bullying is associated with both job-related and health- and well-being-related out- 
comes, such as mental and physical health problems, symptoms of post-traumatic stress, burnout, increased intentions to leave, and reduced job satisfaction and organizational commitment. Contrary to face-to-face bullying, the consequences of cyberbullying in working life have not yet been studied to a greater extent, but its impact can be assumed to be similar (West, Foster, Levin, Edmison, \& Robibero, 2014).

\subsection{Measuring Face-to-Face Bullying and Cyberbullying}

When it comes to measuring face-to-face bullying, different kinds of questionnaires have been used (Nielsen \& Einarsen, 2012). One of the most frequently used (at least in a European context) is the Negative Acts Questionnarie-revised (NAQ-R) developed by (Einarsen et al., 2009). The NAQ-R consists of 22 items that are divided into three different factors; work-related bullying, person-related bullying and physically intimidating bullying.

Since cyberbullying behavior in working life is a relatively new phenomenon, there are a limited number of studies where questionnaires actually have been used. Tokunaga (2010) stresses the fact that while several instruments to access cyberbullying have been developed since 2004, there is nevertheless a lack of knowledge about their psychometric properties. In addition, nearly all studies have been focusing on either middle school or adolescence (Berne et al., 2012). According to Tokunaga (2010), the most pervasive methodological drawback in cyberbullying research is related to the varying conceptualization of cyberbullying. The inconsistent use of operational measures between studies is equally as troubling as the absence of a universal cyberbullying definition.

Tokunaga (2010) implies that researchers in the area of cyberbullying among youngsters tend to develop their own instrument without providing a rationale for its necessity or superiority over other scales already proposed. Cyberbullying occurrence is most frequently operationalized in the form of one- or two-item measures based on dichotomous choice (yes/no responses), following a supplied definition of face-to-face bullying, cyberbullying, or both (Tokunaga, 2010). As most of the studies have focused on children and adolescents there is a lack of research about cyberbullying among adults in working life (Berne et al., 2013).

In the few studies focusing on cyberbullying among adults, scales that were originally developed to measure face-face bullying such as NAQ-R has been modified in order to measure the aspects of cyberbullying (Privitera \& Campbell, 2009; Sprigg et al., 2012). In an exploratory studyby Sprigg et al. (2012) with the aim of developing a cyberbullying negative act questionnaire NAQ-R-items were rated by three subject-matter experts regarding the extent to which they agreed that each item could be enacted over various electronic media: 1) Text messaging, 2) Pictures/photos or video clips, 3) Phone calls, 4) Email, 5) Chat rooms, 6) Instant messaging, 7) Websites. These seven electronic media were included as they were identified by Smith et al. (2008) as the most common media that perpetrators used when engaging in cyberbullying behaviors. In order to find out how cyberbullying behaviours in working life are expressed, a study among 
working adults in Sweden was conducted (Forssell, 2014). The study included an online questionnaire that consisted of 12 open-ended questions: background questions (gender, profession, and supervisory position), experience of harassment via digital media by colleagues, supervisors, customer/client, and the experience of witnessing cyberbullying behavior. The open-ended questionnaire identified 11 different types of cyberbullying behaviors.

As described above, there is little research concerning online cyberbullying in working life and conscequently there is a lack of available, reliable and valid questionnaires/scales. Thus, we argue that there is a need for at least two different types of instruments. One that can be used in studies where the sole focus is on cyberbullying behavior in working life and a modified shorter version that can easily be used in conjunction with other work environment scales.

The aim of this study is two folded: 1) to analyze the reliability and validity of a cyberbullying behaviour questionnaire (CBQ) in working life and 2) to analyze the reliability and validity of a short version of a cyberbullying behaviour questionnaire (CBQ-S) in working life.

\section{Method}

As we wanted to avoid that the reliability and validity analyses of the CBQ and CBQ-S would not apply only to Swedish worklife context, the data was gathered both in Sweden and the USA.

\subsection{Participants and Procedure in Sweden}

A total of 3371 individuals completed the CBQ, $49 \%$ of the participants were women and the mean age was 50 years $(\mathrm{SD}=9.63)$. A majority $(60 \%)$ had university education and were working full-time ( $82 \%)$. Also, a majority $(73 \%)$ reported that they used digital tools (computer, mobile phone, iPad etc.) very often or always at their work.

The data were collected by TNS Sifo, a public opinion poll and market research company. TNS Sifo has an online web panel consisting of a nationally representative random sample of 140,000 people aged 16 years or older. The questionnaire was distributed to a random sample of individuals resident in Scania, Southern Sweden aged between 25 and 65 .

The data was collected between 17 April and 20 May 2014. Altogether 3885 individuals responded but since the aim of the study was to assess cyberbullying behaviour at work, individuals who had been unemployed during the last six months $(\mathrm{n}=514)$ were excluded from the study. The total number of participants in the Swedish sample was therefore 3371 giving a response rate of $42 \%$.

\subsection{Participants and Procedure in the USA}

The English version of the CBQ was distributed through Amazon's Mechanical Turk from 15 September to 16 October 2014. Selection criteria were that the respondents had to be US citizens and had to have demonstrated a high degree of accuracy in earlier surveys (what is called Masters distinction). Altogether 240 
responses were received after four weeks. Two of the respondents were excluded from the sample since they had not been working during the last six months. The mean age was 36 years ( $S D=10.13$ ), and $49 \%$ of the participants were women. A majority of the respondents $(68 \%)$ had a university education and $31 \%$ had a supervisory position.

\subsection{Measures}

\subsubsection{The Cyberbullying Behaviour Questionnaire (CBQ and CBQ-S)}

As described earlier, there are little research in the area of measuring cyberbullying (both among children and among adults). In order to develop a questionnaire measruing cyber bullying, an existing measurement of face-to-face bullying, the NAQ-R (Einarsen, Hoel, \& Notelaers, 2009; Strandmark, Nordström, Wilde Larsson, \& Rystedt, 2013), a preliminary questionnaire of cyberbullying, the Cyber Negative Acts Questionnaire (Sprigg et al., 2012), and the results of the study by Forssell (2014) functioned as the basis of the CBQ (see Table 1).

Table 1. Items in the CBQ (CBQ-S items in bold).

How often during the last six months has any of the following occurred:

1. Your supervisor/colleagues are not responding to your e-mails or text messages ${ }^{\mathrm{a}, \mathrm{b}}$

2. Your work performance has been commented upon in negative terms on the Internet ${ }^{\mathrm{b}, c}$

3. Rude messages have been sent to you via digital media ${ }^{c}$

4. Persistent criticism of your work or performance has been made against you via digital media ${ }^{\mathrm{a}}$

5. Necessary information has been withheld making your work more difficult (e.g. being excluded from e-mail lists) ${ }^{a, b, c}$

6. Aggressively worded messages (e.g. capital letters, bold style or multiple exclamation marks) have been sent to you via e-mail, text messages or the like $\mathrm{b}^{\mathrm{b}}$

7. Threatening personal messages have been sent to you via digital media ${ }^{\mathrm{a}, \mathrm{b}}$

8. Allegations about you have been made on the Internet ${ }^{\mathrm{a}}$

9. Threatening messages about your friends/your family have been sent to you via digital media ${ }^{c}$

10. Others have commented on the Internet that you should quit your work ${ }^{\mathrm{a}}$

11. Attacks against you as a person, your values or your personal life have been made on digital mediac ${ }^{c}$

12. Your computer identity has been hijacked ${ }^{c}$

13. Gossip or rumors about you have been spread on the Internet ${ }^{\mathrm{a}}$

14. Extracts from your messages have been copied so that the meaning of the original message is distorted $^{\mathrm{b}}$

15. Offensive photos/videos of you have been posted on the Internet

16. Jokes about you have been spread on the Internet or via e-mail to several recipients ${ }^{\mathrm{a}}$

17. Viruses have intentionally been sent to your e-mail address ${ }^{c}$

18. Your mistakes or errors at work are repeatedly commented about in e-mails, text messages, or the like $\mathrm{a}^{\mathrm{a}, \mathrm{c}}$

19. False statements about you have been spread on the Internet ${ }^{a}$

20. Colleagues have excluded you from the social community online (e.g. Facebook, Twitter) ${ }^{\mathrm{a}}$

${ }^{\mathrm{a}}=$ NAQ-R, Einarsen et al., 2009, ${ }^{\mathrm{b}}=$ Sprigg et al., 2012, ${ }^{\mathrm{c}}=$ Forssell, 2014 
The CBQ consists of 20 items covering a wide range of work-related cyberbullying behaviour (see Table 1). The CBQ-S consists of seven items from the CBQ (see Table 1 marked in bold).

This instruction was given to the respondents: "The following behaviours are often seen as examples of negative behaviour in the workplace that may occur via the use of technology. When responding consider every act in relation to these eight types of technologies: Text messaging; pictures/photos or video clips, phone calls; email; chat rooms; instant messaging; websites; and social networking websites (e.g. Facebook, Twitter, YouTube).

"Over the last six months, how often have you been subjected to the following negative acts related to your work through different forms of technology?"

The respondents rated the items on a five-point scale, $1=$ never, $2=$ now and then, 3 = monthly, 4 = weekly, 5 = daily (Einarsen et al., 2009; Sprigg et al., 2012). The items in the questionnaire were in Swedish, but they were translated into English for the US sample, and thereafter back-translated to ensure the correct wording of them.

In order to conduct a criterion validity test, the following measurement were included. These measurement have in research shown a prior relationship with face-to-face bullying (Nielsen and Einarsen, 2012).

Wellbeing was measured by General Health Questionnaire 12 (GHQ-12) originally developed by Goldberg (1972), and a Swedish version developed by Sconfienza (Sconfienza, 1998). A sample item is: "I have been able to face up my problems." The respondents rated the items on a four-point scale from 1 (=Disagree very much) to 4 (=Agree very much). Cronbach's alpha was 0.76 in the Swedish sample and 0.95 in the US sample.

Work engagement was assessed by a short form of the Utrecht Work Engagement Scale (UWES-9) (Schaufeli, Bakker, \& Salanova, 2006). An example is: "I am enthusiastic about my job." The responses were rated on 7-point scale from 1 (=never) to 7 (=always). Cronbach's alpha was .95 in Sweden and 0.96 in the US.

Intention to quit was measured by one item: "How often do you consider looking for work somewhere else?” (Berthelsen, Westerlund, \& Söndergård, 2014; Pejtersen, Kristensen, Borg, \& Bjorner, 2010). Ratings were made on a 5 -point scale from 1 (=very seldom) to 5 (=very often).

\subsubsection{Analyses}

To investigate the psychometric evaluation of CBQ and CBQ-S, four different kinds of statistics were calculated. Descriptive statistics, mean, SD for the total group and also separately for men and women. Exploratory Structural Equation Modeleling (ESEM) were conducted to test the number of factors and their loadings on items. It was based on estimations using the MPlus software (Muthén \& Muthén, 2007). To estimate the reliability of the scales, ordinal alpha was estimated with R-program (Gardemann, Ghun, \& Zumbo, 2012) and last, to analyze criterion validity, correlations between the scale and the theoretically relevant concepts (wellbeing, work engagemant, and intention to quit) were con- 
ducted. The distribution of $\mathrm{CBQ}$ and $\mathrm{CBQ}-\mathrm{S}$ was very skewed, therefore all statistical test using CBQ and CBQ-S were based on the robust estimations (MLR) in the MPlus program (ESEM was estimated with WLSMV that also took care of skewed distributions).

\section{Results}

\subsection{CBQ}

\subsubsection{Means and Standard Deviations of the CBQ}

Table 2 illustrates the means and standard deviations for the individual items, the totals for all participants and for men and women respectively, for both the Swedish and the US sample. As regards the Swedish sample, the robust estimation showed a significant difference between men $(M=1.63, \mathrm{SD}=2.89)$ and women $(M=1.27, \mathrm{SD}=2.55)$ concerning the total score of perceived online negative acts; $(\Delta M / S . E=0.036 / 0.09=4.12, p<0.001)$. The result indicates that men were more exposed to cyberbullying behaviour than women in Sweden. However, no significant gender differences were found in the US sample concerning the total score of perceived online negative acts: men $(\mathrm{M}=4.85, \mathrm{SD}=$ $5.67)$ and women $(\mathrm{M}=3.66, \mathrm{SD}=5.27), \Delta M / S . E .=-0.120 / 0.71=1.68, p=$ 0.092).

\subsubsection{Exploratory Structural Equation Modeleling (ESEM)}

To test the factor structure of the cyber bullying questionnaire we used ESEM. To remedy the very obvious skewness of items, we defined them as ordered categories and used Weighted Least Square (WLSMV) for the estimation. In addition, because some (see Table 3) of the items lacked ratings on the two highest rating categories, we reduced the number of categories from 5 to 3 by collapsing the three highest rating categories into a single category. The whole rating scale was also moved by 1 point with a new range from 0 to 2 . The value 0 corresponded better the rating "never". The analysis started with the one-factor model, since this is the most parsimonous. It was found that this model had excellent fit to the data; $\chi^{2}(170)=986.7, p<0.001, \mathrm{CFI}=0.97$ and RMSEA $=0.037$. Standardized loadings (see Table 4 ) were very high for most of the items, the five items with lowest loadings were \#1, \#5, \#12, \#17, and \#20, but all except \#17 had loadings that were above 0.50 . We also tested a model with fewer categories by collapsing the five highest categories into a single category ( 0 and 1$)$; this did not influence the results of the ESEM estimations. Since the fit for the one-factor model was so good we did not test other models with a higher number of factors.

The same ESEM model was used to test the homogeneity of the scale from the US sample. In this sample too, the highest three categories were used very rarely (see Table 3), and therefore they were collapsed into one and the rating scale moved by one point for a new range of 0 to 2 . It was found that the one-factor ESEM model had a excellent fit to the data, $\chi^{2}(170)=446.2$, CFI $=0.98$ and RMSEA $=0.083$. The loadings were very high for all items ( 0.61 and above) except for two items (\#1 and \#17) that were 0.48 and 0.32 (see Table 5). The latter 
S. Jönsson et al.

Table 2. Means and standard deviations of CBQ for totals, individual items, for men and women separately both for the Swedish and the US sample.

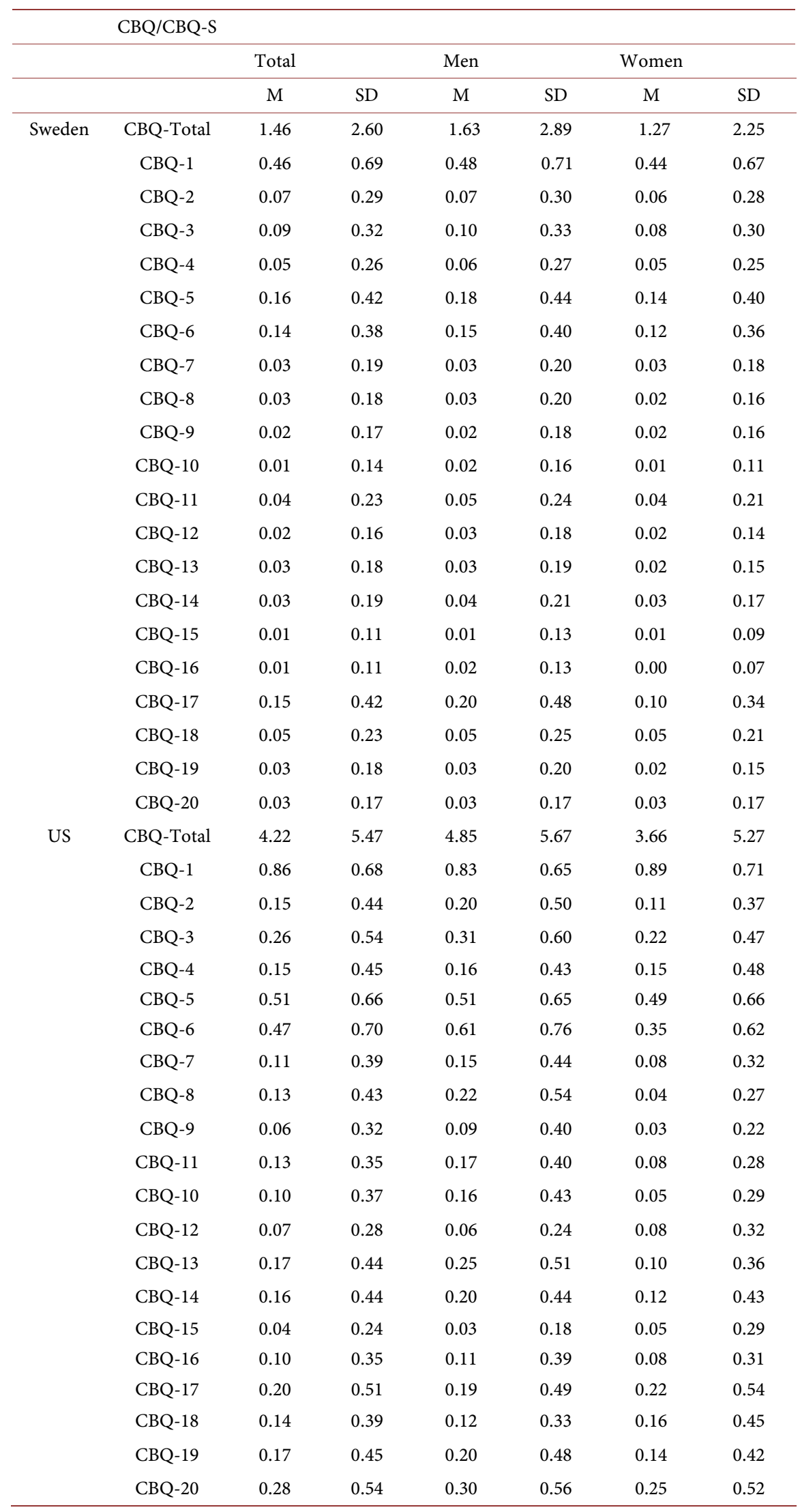


Table 3. Frequency (\%) of responses in the Swedish and US sample, items in bold represents item in the short scale.

\begin{tabular}{|c|c|c|c|c|c|c|c|}
\hline \multicolumn{8}{|c|}{ CBQ/CBQ-S } \\
\hline & & Never & $\begin{array}{l}\text { Now } \\
\text { and } \\
\text { then }\end{array}$ & Monthly & Weekly & Daily & Missing \\
\hline \multirow[t]{20}{*}{ Sweden } & CBQ-1 & 65.3 & 23.1 & 3.7 & 4.7 & 3.0 & 0.2 \\
\hline & CBQ-2 & 92.1 & 4.5 & 0.5 & 0.3 & 0.2 & 2.4 \\
\hline & CBQ-3 & 91.7 & 6.4 & 0.6 & 0.3 & 0.1 & 0.9 \\
\hline & CBQ-4 & 94.7 & 3.4 & 0.4 & 0.2 & 0.2 & 1.0 \\
\hline & CBQ-5 & 85.3 & 11.8 & 1.4 & 0.6 & 0.1 & 0.8 \\
\hline & CBQ-6 & 86.7 & 10.9 & 1.0 & 0.3 & 0.1 & 1.0 \\
\hline & CBQ-7 & 96.6 & 2.3 & 0.2 & 0.1 & 0.0 & 0.8 \\
\hline & CBQ-8 & 96.4 & 2.3 & 0.1 & 0.1 & 0.0 & 1.1 \\
\hline & CBQ-9 & 96.9 & 1.8 & 0.2 & 0.0 & 0.0 & 1.0 \\
\hline & CBQ-10 & 97.8 & 1.0 & 0.2 & 0.0 & 0.0 & 1.0 \\
\hline & CBQ-11 & 95.8 & 3.5 & 0.1 & 0.2 & 0.1 & 0.2 \\
\hline & CBQ-12 & 97.1 & 2.3 & 0.1 & 0.0 & 0.0 & 0.5 \\
\hline & CBQ-13 & 97.2 & 2.2 & 0.1 & 0.1 & 0.0 & 0.4 \\
\hline & CBQ-14 & 96.1 & 3.1 & 0.1 & 0.0 & 0.0 & 0.7 \\
\hline & CBQ-15 & 98.5 & 0.8 & 0.0 & 0.0 & 0.1 & 0.7 \\
\hline & CBQ-16 & 98.3 & 0.9 & 0.1 & 0.0 & 0.0 & 0.7 \\
\hline & CBQ-17 & 86.4 & 10.5 & 1.3 & 0.8 & 0.2 & 0.8 \\
\hline & CBQ-18 & 94.6 & 4.4 & 0.2 & 0.0 & 0.0 & 0.8 \\
\hline & CBQ-19 & 96.9 & 2.2 & 0.1 & 0.1 & 0.0 & 0.7 \\
\hline & CBQ-20 & 96.7 & 2.5 & 0.1 & 0.0 & 0.0 & 0.7 \\
\hline \multirow[t]{20}{*}{ US } & CBQ-1 & 30.7 & 51.3 & 7.1 & 8.4 & 1.3 & 1.3 \\
\hline & CBQ-2 & 85.7 & 9.2 & 1.7 & 0.8 & 0.4 & 2.1 \\
\hline & CBQ-3 & 77.3 & 16.8 & 1.7 & 2.9 & 0.0 & 1.3 \\
\hline & CBQ-4 & 87.4 & 7.1 & 2.1 & 1.7 & 0.0 & 1.7 \\
\hline & CBQ-5 & 58.0 & 32.8 & 6.7 & 1.7 & 0.4 & 0.4 \\
\hline & CBQ-6 & 63.9 & 23.5 & 7.6 & 4.2 & 4.2 & 0.8 \\
\hline & CBQ-7 & 90.3 & 5.9 & 1.3 & 1.3 & 0.0 & 1.3 \\
\hline & CBQ-8 & 90.3 & 5.0 & 2.5 & 1.3 & 0.0 & 0.8 \\
\hline & CBQ-9 & 95.0 & 2.1 & 0.8 & 1.3 & 0.0 & 0.8 \\
\hline & CBQ-10 & 92.0 & 5.9 & 0.8 & 1.3 & 0.0 & 0.0 \\
\hline & CBQ-11 & 87.8 & 11.8 & 0.0 & 0.4 & 0.0 & 0.0 \\
\hline & CBQ-12 & 94.1 & 5.0 & 0.8 & 0.0 & 0.0 & 0.0 \\
\hline & CBQ-13 & 84.0 & 12.2 & 1.3 & 1.3 & 0.0 & 1.3 \\
\hline & CBQ-14 & 87.0 & 9.7 & 2.5 & 0.4 & 0.0 & 0.4 \\
\hline & CBQ-15 & 96.2 & 2.5 & 0.4 & 0.4 & 0.0 & 0.0 \\
\hline & CBQ-16 & 91.6 & 6.3 & 0.4 & 1.3 & 0.0 & 0.0 \\
\hline & CBQ-17 & 84.9 & 10.1 & 2.5 & 1.7 & 0.8 & 0.0 \\
\hline & CBQ-18 & 86.6 & 10.5 & 0.8 & 0.8 & 0.0 & 1.3 \\
\hline & CBQ-19 & 85.3 & 10.9 & 2.1 & 0.8 & 0.0 & 0.8 \\
\hline & CBQ-20 & 76.5 & 18.5 & 3.8 & 0.8 & 0.0 & 0.4 \\
\hline
\end{tabular}


Table 4. Item loadings and corrected item total correlations.

\begin{tabular}{ccccc}
\hline CBQ & $\begin{array}{c}\text { Swedish item } \\
\text { loading }\end{array}$ & $\begin{array}{c}\text { Swedish corrected } \\
\text { item total } \\
\text { correlation }\end{array}$ & US item loading & $\begin{array}{c}\text { US corrected item } \\
\text { total correlation }\end{array}$ \\
\hline CBQ-1 & 0.54 & 0.53 & 0.48 & 0.49 \\
CBQ-2 & 0.76 & 0.73 & 0.81 & 0.77 \\
CBQ-3 & 0.80 & 0.79 & 0.78 & 0.78 \\
CBQ-4 & 0.83 & 0.81 & 0.81 & 0.79 \\
CBQ-5 & 0.59 & 0.60 & 0.66 & 0.69 \\
CBQ-6 & 0.71 & 0.72 & 0.76 & 0.76 \\
CBQ-7 & 0.86 & 0.85 & 0.99 & 0.94 \\
CBQ-8 & 0.87 & 0.86 & 0.89 & 0.84 \\
CBQ-9 & 0.81 & 0.83 & 0.95 & 0.86 \\
CBQ-10 & 0.86 & 0.85 & 0.88 & 0.85 \\
CBQ-11 & 0.75 & 0.75 & 0.80 & 0.77 \\
CBQ-12 & 0.58 & 0.60 & 0.67 & 0.70 \\
CBQ-13 & 0.85 & 0.84 & 0.86 & 0.84 \\
CBQ-14 & 0.72 & 0.77 & 0.82 & 0.83 \\
CBQ-15 & 0.75 & 0.78 & 0.76 & 0.79 \\
CBQ-16 & 0.79 & 0.89 & 0.80 & 0.77 \\
CBQ-17 & 0.43 & 0.47 & 0.32 & 0.36 \\
CBQ-18 & 0.71 & 0.74 & 0.77 & 0.75 \\
CBQ-19 & 0.86 & 0.86 & 0.86 & 0.64 \\
CBQ-20 & 0.51 & 0.65 & & \\
\hline & & & 0.61 & \\
\hline
\end{tabular}

Table 5. Correlations between $\mathrm{CBQ}$, work engagement, wellbeing, and intention to quit.

\begin{tabular}{ccccc}
\hline Measure & 1 & 2 & 3 & 4 \\
\hline 1. CBQ & - & -0.10 & $-0.30^{* *}$ & $0.20^{*}$ \\
2. Work engagement & $-0.10^{\star *}$ & - & $0.55^{\star *}$ & $-0.61^{* *}$ \\
3. Wellbeing & $-0.21^{* *}$ & $0.55^{* *}$ & - & $-0.44^{* *}$ \\
4. Intention to quit & $0.19^{* *}$ & $0.49^{* *}$ & $-0.46^{* *}$ & - \\
\hline
\end{tabular}

Note: ${ }^{\star} p<0.01,{ }^{* *} p<0.001$. Swedish sample below the diagonal, US sample above the diagonal.

fit indices were above the recommended level for a good fit, but since the CFI was very close to 1 , it is suggested that almost all of the covariance between the items could be explained by one single factor ${ }^{1}$.

\subsubsection{Reliability of the $\mathrm{CBQ}$}

To calculate the reliability of the scale we used the R-program (Gardemann, Ghun, \& Zumbo, 2012) and the psych-package to first calculate a polychoric correlation matrix. Based on this matrix we calculated alpha, which was found to be 0.96 , suggesting the scale to be very reliable. The corrected scale item correlations (see Table 4) were very similar to the loadings from the ESEM.

${ }^{1}$ We made a configural invariance testing and found that the two samples did not differ much $p>$ 0.001 . 
Regarding the US sample of the inventory, the alpha, based on the polychoric correlation matrix, was 0.96 , suggesting this version to be as reliable as the original Swedish questionnaire.

\subsubsection{Criterion Validity of the $\mathrm{CBQ}$}

To measure the criterion validity correlation coefficients based on robust estimations between $\mathrm{CBQ}$ and scales measuring work engagement, wellbeing and intentions to quit were estimated (see Table 5). The results showed that cyberbullying behaviour correlated negatively with work engagement and wellbeing. There was a positive correlation between cyberbullying behaviour and intention to quit. $\mathrm{CBQ}$ had a negative correlation with wellbeing and a positive correlation with intention to quit in the US sample. The results were similar for both samples, except that the correlation between $\mathrm{CBQ}$ and work engagement was not significant for the US sample.

\subsection{CBQ-S}

We created the short scale by selecting items based on two criteria, first that the items substantly contributed to the variation of the scale, and second that the items represented the core of cyberbulling.

Table 3 includes the frequency of responses in the Swedish and US sample to each rating category for all items. It is obvious that the most common respons was "never" of the behavior. For some of the items, hardly no one revealed that they had experienced the behavior.

To select in accordance with the first criteria, items were selected if they contributed substantially in a regression analysis, having the total scale as dependent and all the items as independents. Among those items having a high regression weights we seleted a subset that represented the largest range of behaviors. The short set consists of seven items (see bold in Table 1). They represented $95.1 \%$ of the variance of a scale consisting of all 20 items included in the first version.

\subsubsection{Means and Standard Deviations of the CBQ-S}

See Table 6 for means and standard deviations. As regards the Swedish sample, there was a small but significant difference between men $(M=1.19, S D=1.92)$ and women $(M=1.03, S D=1.71)$ concerning the total score of perceived online negative acts, $(\Delta M / S . E .=-0.16 / 0.05=3.08, p=0.002)$. The result indicates that men were somewhat more exposed to cyberbullying behaviour than women in Sweden. However, no gender differences were found in the US sample concerning the total score of perceived cyberbullying behaviour: men $(M=2.74, S D=$ 3.56) and women, $\Delta M / S . E .=-0.52 / 0.33=3.08, p=0.107$, but note that the trend is the same and that the US sample is much smaller.

\subsubsection{Exploratory Structural Equation Modeleling (ESEM) of the CBQ-S} When conducting the ESEM for the CBQ-S, the same preliminary adjustements as with the CBQ were made. The three highest rating categories were collapse into one and the whole rating scale was moved by one point for a new range 0 to 
Table 6. Means and standard deviations of CBQ-S for totals, individual items, for men and women separately both for the Swedish and the US sample.

\begin{tabular}{cccccccc}
\hline \multirow{4}{*}{ Sweden } & CBQ-S & $\mathrm{M}$ & $\mathrm{SD}$ & $\mathrm{M}$ & $\mathrm{SD}$ & $\mathrm{M}$ & $\mathrm{SD}$ \\
\hline & CBQ-total & 0.96 & 1.51 & 1.03 & 1.60 & 0.88 & 1.42 \\
& CBQ-1 & 0.46 & 0.69 & 0.48 & 0.71 & 0.44 & 0.67 \\
& CBQ-2 & 0.07 & 0.29 & 0.07 & 0.30 & 0.06 & 0.28 \\
& CBQ-3 & 0.09 & 0.32 & 0.10 & 0.33 & 0.08 & 0.30 \\
& CBQ-5 & 0.16 & 0.42 & 0.18 & 0.44 & 0.14 & 0.40 \\
& CBQ-6 & 0.14 & 0.38 & 0.15 & 0.40 & 0.12 & 0.36 \\
& CBQ-9 & 0.02 & 0.17 & 0.02 & 0.18 & 0.02 & 0.16 \\
& CBQ-19 & 0.03 & 0.18 & 0.03 & 0.20 & 0.02 & 0.15 \\
& CBQ-total & 2.47 & 2.25 & 2.74 & 2.74 & 2.22 & 2.26 \\
& CBQ-1 & 0.86 & 0.68 & 0.83 & 0.65 & 0.89 & 0.71 \\
& CBQ-2 & 0.15 & 0.44 & 0.20 & 0.50 & 0.11 & 0.37 \\
& CBQ-3 & 0.26 & 0.54 & 0.31 & 0.60 & 0.22 & 0.47 \\
& CBQ-5 & 0.51 & 0.66 & 0.51 & 0.65 & 0.49 & 0.66 \\
& CBQ-6 & 0.47 & 0.70 & 0.61 & 0.76 & 0.35 & 0.62 \\
& CBQ-9 & 0.06 & 0.32 & 0.09 & 0.40 & 0.03 & 0.22 \\
& CBQ-19 & 0.17 & 0.45 & 0.20 & 0.48 & 0.14 & 0.42 \\
\hline
\end{tabular}

2. Here, it was found that a one-factor CFA model had excellent fit to the data; $\chi^{2}(14)=124.9$, CFI $=0.96$ and RMSEA $=0.048$. Standardized loadings (see Table 7) were high. All items had a very high loading above 0.73 except for two items (\#1 and \#5) that had a loading of 0.55 and 0.56 . Even if the fit was excellent we consulted the modification indices and found that one correlation between the error of item 1 and item 5 was high, $\chi^{2}(1)=90.8$. We added this correlation to the model and found that the correlation was moderate in size $(\operatorname{stdxy}=0.338)$ and that the new model was significantly better, Santora Bentler corrected difference in $\chi^{2}(1)$ was 53.5, $p<0.001$. Since we now had almost perfect fit we did not test models with more factors. The content of the items were similar as both mentioned e-mail, a possible casue of this correlation.

The same ESEM was used to test the homogeneity of the scale from the US sample. In this sample too, the highest three categories were used very rarely, and therefore they were collapsed into one and the rating scale moved by one point for a new range of 0 to 2. It was found that the one-factor ESEM model had a excellent fit to the data, $\chi^{2}(14)=32.3$, CFI $=0.97$ and RMSEA $=0.074$ (probability $=0.108$ that RMSEA $\leq 0.05$ ). The standardized loadings were high for all items ( 0.71 and above), the lowest was 0.50 for item 1. Also in the US sample the correlation between item 1 and item 5 was significant, when added to the model the corrected difference in $\chi^{2}(1)$ was $9.77, p=0.002$, CFI $=0.99$, and RMSEA $=0.054$. Given this very close fit we did not test for more factors.

\subsubsection{Reliability of the CBQ-S}

To calculate the reliability of the scale we used the R-program (Gardemann, 
Table 7. CBQ-S Item loadings and corrected item total correlations.

\begin{tabular}{ccccc}
\hline CBQ-S & $\begin{array}{c}\text { Swedish } \\
\text { item loading }\end{array}$ & $\begin{array}{c}\text { Swedish corrected } \\
\text { item total } \\
\text { correlation }\end{array}$ & $\begin{array}{c}\text { English } \\
\text { item loading }\end{array}$ & $\begin{array}{c}\text { English } \\
\text { corrected item total } \\
\text { correlation }\end{array}$ \\
\hline CBQ-1 & 0.56 & 0.59 & 0.50 & 0.53 \\
CBQ-2 & 0.75 & 0.68 & 0.71 & 0.73 \\
CBQ-3 & 0.85 & 0.83 & 0.82 & 0.79 \\
CBQ-5 & 0.55 & 0.61 & 0.59 & 0.65 \\
CBQ-6 & 0.78 & 0.75 & 0.83 & 0.78 \\
CBQ-9 & 0.74 & 0.74 & 0.96 & 0.85 \\
CBQ-19 & 0.75 & 0.75 & 0.73 & 0.86 \\
\hline
\end{tabular}

Ghun, \& Zumbo, 2012) and the psych-package to first calculate a polychoric correlation matrix. Based on this matrix we calculated alpha, which was found to be .88 , suggesting the scale to be very reliable. The corrected scale item correlations (see Table 7) were very similar to the loadings from the CFA.

Regarding the US sample of the inventory, the alpha, based on the polychoric correlation matrix, was 0.88 , suggesting this version to be as reliable as the original Swedish questionnaire.

\subsubsection{Criterion Validity of the CBQ-S}

To measure the criterion validity correlation coefficients based on a robust model between CBQ-S and wellbeing, work engagement, and intentions to quit were estimated.

The results showed that in the Swedish sample (see Table 8) cyberbullying behaviour correlated negatively with work engagement and wellbeing, in addition there was a positive correlation between cyberbullying behaviour and intention to quit. The results were similar for both versions of the questionnaire but only the correlation between CBQ-S and work wellbeing and intention to quit was significant for the US sample.

\section{Discussion}

Communication in today's workplaces takes place to a greater extent electronically, which has given rise to a new phenomenon, cyberbullying behavior in working life. Even though cyberbullying among children and adolescents has been studied and measured in several studies, there is lack of research assessing this behavior among adults in work life. The aim of this study was to analyze the reliability and validity of the scales $\mathrm{CBQ}$ and CBQ-S that assess cyberbullying behaviour in working life. Since there is no existing reliable scale measuring work-related cyberbullying behavior, as far as we know, the results of the study can be regarded as promising. The analyses of the scales were successful in that a one-factor model had excellent fit to the data and that Cronbach's alpha showed that both scales were reliable in both the Swedish and US sample. In addition, criterion validity was found as both $\mathrm{CBQ}$ and CBQ-S correlated significantly 
Table 8. Correlations between CBQ-S, work engagement, wellbeing, and intention to quit.

\begin{tabular}{ccccc}
\hline Measure & 1 & 2 & 3 & 4 \\
\hline 1. CBQ-S & - & -0.09 & $-0.25^{* *}$ & $0.15^{*}$ \\
2. Work engagement & $-0.12^{* *}$ & - & $0.55^{* *}$ & $-0.61^{* *}$ \\
3. Wellbeing & $-0.22^{* *}$ & $0.55^{* *}$ & - & $-0.44^{* *}$ \\
4. Intention to quit & $0.23^{* *}$ & $-0.49^{* *}$ & $-0.46^{* *}$ & - \\
\hline
\end{tabular}

with theoretically relevant concepts; wellbeing, work engagement and intention to quit in the Swedish sample. Same criterion validity was found for the US except for the relationship with work engagement.

It seems therefore that the impact of cyberbullying is similar to that of faceto-face bullying (West et al., 2014).

The two scales can be used in somewhat different ways. If the aim is capture the broad aspect of cyberbullying behavior then the CBQ scale is recommended. The CBQ scales consist of 20 items that cover a wider range of different types of cyberbullying behaviors. If individual subjects are investigated, these 20 items could be used as a check-list of different kind of cyberbullying behavior. The short version consists of as few as seven items, but likewise, this scale encompassed most of the variability. The CBQ-S would be most useful when combined with other scales measuring work environment. The CBQ-S with its seven items is more easily implemented with other battery of questionnaires do to its less time consuming nature. It is important to note though that this version does not include all types of cyberbullying behavior, in this respect the CBQ with its 20 items is more comprehensive.

There are some strengths and limitations of the study that need to be addressed. One strength of this study is that one of the samples was a random sample of individuals resident in Scania, Southern Sweden. This is relevant since the scale has been related to organizational aspects such as work engagement and intention to quit. If the sample had been drawn from only one or a couple of organizations, the results of the study would have been more difficult to generalize to different organizational settings. A limitation of the study is that the US sample was somewhat limited in size and did not include the same questions about the demographic variables as the Swedish questionnaire and cannot be regarded as representative, but the American scale resulted in a similar factor structure. On the other hand, it is not possible to draw any conclusions on differences between Sweden and USA in number of cyberbullying behaviors experienced, the two samples are too different for such comparisons. The results indicate that men were somewhat more exposed to cyberbullying behavior than women in the Swedish sample, whereas no gender difference was found in the US sample. In order to understand these results, further studies focusing on qualitative aspects of online harassment need to be conducted. Another limitation is that fact that we only had a limited number of scales that could be used for the validation of CBQ and CBQ-S. In this study, we chose to work with concepts that have been used for validity tests in studies of face-to-face workplace bully- 
ing. In future studies, other concepts and scales can be added in relation to the validity tests.

\section{Acknowledgements}

This research was supported by a grant from Swedish Research Council for Health, Working Life and Welfare (Forte). DNR: 2012-0230.

\section{Competing Interest}

The authors declare that they have no competing interests in publishing this article.

\section{Ethics and Consent}

The study was approved by the Regional Ethical Review Board, Lund, Southern Sweden $(2012 / 619)$.

\section{References}

Agervold, M. (2007). Bullying at Work: A Discussion of Definitions and Prevalence, Based on an Empirical Study. Scandinavian Journal of Psychology, 48, 161-172. https://doi.org/10.1111/j.1467-9450.2007.00585.x

Bartlett, J. E., \& Bartlett, M. E. (2011). Workplace Bullying: An Integrative Literature Review. Advances in Developing Human Resources, 13, 69-84. https://doi.org/10.1177/1523422311410651

Baruch, Y. (2005). Bullying on the Net: Adverse Behavior on Email and Its Impact. Information \& Management, 42, 361-371. https://doi.org/10.1016/j.im.2004.02.001

Beran, T., \& Li, Q. (2005). Cyber-Harassment: A Study of a New Method for an Old Behavior. Journal of Educational Computing Research, 32, 265-277. https://doi.org/10.2190/8YQM-B04H-PG4D-BLLH

Berne, S., Frisén, A., Schultze-Krumbholz, A., Scheithauer, H., Naruskov, K., Luik, P., et al. (2013). Cyberbullying Assessment Instruments: A Systematic Review. Aggression and Violent Behavior, 18, 320-334. https://doi.org/10.1016/j.avb.2012.11.022

Berthelsen, H., Westerlund H., \& Söndergård, T. (2014). Copenhagen Psychosocial Questionnaire II (COPSOQ II)_En preliminär validering av den svenska versionen Stressforskningsinstitutets rapportserie, Stockholms universitet. (Submitted)

Bilgel, N., Aytac, S., \& Bayram, N. (2006). Bullying in Turkish White-Collar Workers. Occupational Medicine, 56, 226-231. https://doi.org/10.1093/occmed/kqj041

Brack, K., \& Caltabiano, N. (2014). Cyberbullying and Self-Esteem in Australian Adults. Cyberpsychology, 8. https://doi.org/10.5817/CP2014-2-7

Einarsen, S., \& Skogstad, A. (1996). Bullying at Work: Epidemiological Findings in Public and Private Organizations. European Journal of Work and OrganizationalPsychology, 5, 185-201. https://doi.org/10.1080/13594329608414854

Einarsen, S., Hoel, H., \& Notelaers, G. (2009). Measuring Exposure to Bullying and Harassment at Work: Validity, Factor Structure and Psychometric Properties of the Negative Acts Questionnaire-Revised. Work \& Stress, 23, 24-44. https://doi.org/10.1080/02678370902815673

Einarsen, S., Hoel, H., Zapf, D., \& Cooper, C. L. (2011). The Concept of Bullying and Harassment at Work: The European Tradition. In S. Einarsen, H. Hoel, D. Zapf, \& C. L. Cooper (Eds.), Bullying and Harassment in the Workplace: Developments in Theory, 
Research, and Practice (2nd Ed., pp. 3-39).

Erdur-Baker, Ö. (2010). Cyberbullying and Its Correlation to Traditional Bullying, Gender and Frequent and Risky Usage of Internet-Mediated Communication Tools. New Media \& Society, 12, 109-125. https://doi.org/10.1177/1461444809341260

Findahl, O. (2014). Swedes and the Internet. http://en.soi2014.se

Forssell, R. (2014). Cyberbullying in Work Life.

Forssell, R. (2016). Exploring Cyberbullying and Face-to-Face Bullying in Working LifePrevalence, Targets and Expressions. Computers in Human Behavior, 58, 454-460. https://doi.org/10.1016/j.chb.2016.01.003

Gardemann, A. M., Ghun, M., \& Zumbo, B. D. (2012). Estimating Ordinal Reliability for Likert-Type and Ordinal Item Response Data: A Conceptual, Empirical, and Practical Guide. Practical Assessment, Research \& Evaluation, 17, 1-13.

Goldberg, D. (1972). The Detection of Psychiatric Illness by Questionnaire: A Technique for the Identification and Assessment of Non-Psychotic Psychiatric Illness. London: Oxford University Press.

Göransson, S., Näswall, K., \& Sverke, M. (2011). Kunskapsöversikt: Psykologiska perspektiv på hot och våld $i$ arbetslivet. Stockholm: Arbetsmiljöverket.

Kowalski, R. M., Giumetti, G. W., Schroder, A. N., \& Lattaner, M. R. (2014). Bullying in the Digital Age: A Critical Review and Meta-Analysis of Cyberbullying Research among Youth. Psychological Bulletin, 140, 1073-1137. https://doi.org/10.1037/a0035618

Leymann, H. (1996). The Content and Development of Mobbing at Work. European Journal of Work and Organizational Psychology, 10, 165-184. https://doi.org/10.1080/13594329608414853

Lim, V. K. G., \& Teo, T. S. H. (2009). Mind Your E-Manners: Impact of Cyber Incivility on Employees' Work Attitude and Behavior. Information \& Management, 46, 419-425. https://doi.org/10.1016/j.im.2009.06.006

Mikkelsen, E. G., \& Einarsen, S. (2001). Bullying in Danish Work-Life: Prevalence and Health Correlates. European Journal of Work and Organizational Psychology, 10, 393413. https://doi.org/10.1080/13594320143000816

Muthén, L. K., \& Muthén, B. O. (2007). Mplus User's Guide (6th ed.). Los Angeles, CA: Muthén \& Muthén.

Nielsen, M. B., \& Einarsen, S. (2012). Outcomes of Exposure to Workplace Bullying: A Meta-Analytic Review. Work \& Stress, 26, 309-332. https://doi.org/10.1080/02678373.2012.734709

Nielsen, M. B., A. Skogstad, A., Matthiesen, S. B., Glasø, L., Aasland, M. S., \& Notelaers, G. (2009). Prevalence of Workplace Bullying in Norway: Comparisons across Time and Estimation Methods. European Journal of Work and Organizational Psychology, 18, 81-101. https://doi.org/10.1080/13594320801969707

Notelaers, G., Vermunt, J. K., Baillien, E., Einarsen, S., \& Witte, H. D. (2011). Exploring Risk Groups and Risk Factors for Workplace Bullying. Industrial Health, 49, 73-88. https://doi.org/10.2486/indhealth.MS1155

Olweus, D. (2013). School Bullying: Development and Some Important Challenges. Annual Review of Clinical Psychology, 9, 751-780. https://doi.org/10.1146/annurev-clinpsy-050212-185516

Pejtersen, J. H., Kristensen, T. S., Borg, V., \& Bjorner, J. B. (2010). The Second Version of the Copenhagen Psychosocial Questionnaire. Scandinavian Journal of Public Health, 38, 8-24. https://doi.org/10.1177/1403494809349858 
Privitera, C., \& Campbell, M. A. (2009). Cyberbullying: The New Face of Workplace Bullying? Cyber Psychology \& Behavior, 12, 395-400.

https://doi.org/10.1089/cpb.2009.0025

Runions, K., Shapka, J. D., Dooley, J., \& Modecki, K. (2013). Cyber-Aggression and Victimization and Social Information Processing: Integrating the Medium and the Message. Psychology of Violence, 3, 9-26. https://doi.org/10.1037/a0030511

Salin, D., \& Hoel, H. (2013). Workplace Bullying as a Gendered Phenomenon. Journal of Managerial Psychology, 3, 235-251. https://doi.org/10.1108/02683941311321187

Schaufeli, W. B., Bakker, A. B., \& Salanova, M. (2006). The Measurement of Work Engagement with a Short Questionnaire a Cross-National Study. Educational and Psychological Measurement, 66, 701-716. https://doi.org/10.1177/0013164405282471

Sconfienza, C. (1998). Mätning av psykiskt välbefinnande bland ungdomar $i$ Sverige Användningen av GHQ-12. Arbete och Hälsa 22.

Slonje, R., \& Smith, P. K. (2008). Cyberbullying: Another Main Type of Bullying? Scandinavian Journal of Psychology, 49, 147-154. https://doi.org/10.1111/j.1467-9450.2007.00611.x

Smith, P. K., Mahdavi, J., Carvalho, M., Fisher, S., Russell, S., \& Tippett, N. (2008). Cyberbullying: Its Nature and Impact in Secondary School Pupils. Journal of Child Psychology and Psychiatry, 49, 376-385. https://doi.org/10.1111/j.1469-7610.2007.01846.x

Sprigg, C., Axtell, C., Coyne, I., \& Farley, S. (2012). Punched from the Screen: Cyberbullying in the Workplace.

Strandmark, M., Nordström, G., Wilde Larsson, B., \& Rystedt, I. (2013). Negativt beteeende på arbetsplatsen. Svensk översättning av NAQ (Negative Acts Questionnaire), Karlstad: Karlstads Universitet.

Tokunaga, R. S. (2010). Following You Home from School: A Critical Review and Synthesis of Research on Cyberbullying Victimization. Computers in Human Behavior, 26, 277-287. https://doi.org/10.1016/j.chb.2009.11.014

Wang, J., Nansel, T. T., \& Iannotti, R. J. (2011). Cyber and Traditional Bullying: Differential Association with Depression. Journal of Adolescent Health, 48, 415-417. https://doi.org/10.1016/j.jadohealth.2010.07.012

West, B., Foster, M., Levin, A., Edmison, J., \& Robibero, D. (2014). Cyberbullying at Work: In Search of Effective Guidance. Laws, 3, 598-617. https://doi.org/10.3390/laws3030598

Wolak, J., Mitchell, K. J., \& Finkelhor, D. (2007). Does Online Harassment Constitute Bullying? An Exploration of Online Harassment by Known Peers and Online-Only Contacts. Journal of Adolescent Health, 41, 51-58. https://doi.org/10.1016/j.jadohealth.2007.08.019

Zapf, D., \& Einarsen, S. (2001). Bullying in the Workplace: Recent Trends in Research and Practice-An Introduction. European Journal of Work and Organizational Psychology, 10, 369-373. https://doi.org/10.1080/13594320143000807

Zapf, D., Escartín, J., Einarsen, S., Hoel, H., \& Vartia, M. (2011). Empirical Findings on Prevalence and Risk Groups of Bullying in the Workplace. In S. Einarsen et al. (Eds.), Bullying and Harassment in the Workplace: Developments in Theory, Research and Practice (pp. 75-105). New York: Taylor \& Francis Group. 
Submit or recommend next manuscript to SCIRP and we will provide best service for you:

Accepting pre-submission inquiries through Email, Facebook, LinkedIn, Twitter, etc. A wide selection of journals (inclusive of 9 subjects, more than 200 journals)

Providing 24-hour high-quality service

User-friendly online submission system

Fair and swift peer-review system

Efficient typesetting and proofreading procedure

Display of the result of downloads and visits, as well as the number of cited articles Maximum dissemination of your research work

Submit your manuscript at: http://papersubmission.scirp.org/

Or contact psych@scirp.org 